\title{
Estimating Remineralized Phosphate and Its Remineralization Rate in the Northern East China Sea During Summer 1997: A Snapshot Study Before Three-Gorges Dam Construction
}

\author{
Hyun-Cheol Kim ${ }^{1}$, Il-Nam Kim ${ }^{2}$, Alison M. Macdonald ${ }^{3}$, Ki-Tae Park ${ }^{4}$, Ju-Hyoung Kim ${ }^{5}$, \\ Joo-Eun Yoon ${ }^{2}$, and Tongsup Lee ${ }^{6, *}$ \\ ${ }^{1}$ Department of Polar Remote Sensing, Korea Polar Research Institute, Incheon, South Korea \\ ${ }^{2}$ Department of Marine Science, Incheon National University, Incheon, South Korea \\ ${ }^{3}$ Woods Hole Oceanographic Institution, Woods Hole, MA, USA \\ ${ }^{4}$ Division of Polar Climate Sciences, Korea Polar Research Institute, Incheon, South Korea \\ ${ }^{5}$ Faculty of Marine Applied Biosciences, Kunsan National University, Kunsan, South Korea \\ ${ }^{6}$ Department of Oceanography, Pusan National University, Busan, South Korea
}

Received 8 September 2015, revised 22 January 2016, accepted 24 January 2016

\begin{abstract}
The northern East China Sea (a.k.a., "The South Sea") is a dynamic zone that exerts a variety of effects on the marine ecosystem due to Three-Gorges Dam construction. As the northern East China Sea region is vulnerable to climate forcing and anthropogenic impacts, it is important to investigate how the remineralization rate in the northern East China Sea has changed in response to such external forcing. We used an historical hydrographic dataset from August 1997 to obtain a baseline for future comparison. We estimate the amount of remineralized phosphate by decomposing the physical mixing and biogeochemical process effect using water column measurements (temperature, salinity, and phosphate). The estimated remineralized phosphate column inventory ranged from 0.8 to $42.4 \mathrm{mmol} \mathrm{P} \mathrm{m}^{-2}$ (mean value of $15.2 \pm 12.0 \mathrm{mmol} \mathrm{P} \mathrm{m}^{-2}$ ). Our results suggest that the Tsushima Warm Current was a strong contributor to primary production during the summer of 1997 in the study area. The estimated summer (June - August) remineralization rate in the region before Three-Gorges Dam construction was $18 \pm 14 \mathrm{mmol} \mathrm{C} \mathrm{m}{ }^{-2} \mathrm{~d}^{-1}$.
\end{abstract}

Key words: Northern East China Sea, Remineralized phosphate, Remineralization rate

Citation: Kim, H. C., I. N. Kim, A. M. Macdonald, K. T. Park, J. H. Kim, J. E. Yoon, and T. Lee, 2016: Estimating remineralized phosphate and its remineralization rate in the northern East China Sea during summer 1997: A snapshot study before Three-Gorges Dam construction. Terr. Atmos. Ocean. Sci., 27, 955-963, doi: 10.3319/TAO.2016.01.24.01(Oc)

\section{INTRODUCTION}

The continental shelf, the interface between land and the open ocean, acts as a biogeochemical reactor that efficiently transforms the bulk of terrigenous material entering its waters into marine chemicals through the combined effects of physical mixing, chemical processing, and vigorous biological activity (Liu et al. 2010). While the continental shelf covers only a tiny fraction of the world's ocean, it has received considerable scientific attention because the "continental shelf pump", which describes the processes that draw down atmospheric $\mathrm{CO}_{2}$ into shelf waters, is expected

\footnotetext{
* Corresponding author

E-mail:tlee@pusan.ac.kr
}

to change rapidly as human activities increase (Tsunogai et al. 1999; Gruber 2015).

The East China Sea (ECS) is one of the largest marginal seas and more than $70 \%$ of its area lies over continental shelf (waters $<200 \mathrm{~m}$ in depth) (Wang et al. 2000). The northern ECS (nECS, locally called the South Sea) is oceanographically dynamic (Fig. 1). Here, the combined effects of heat and salt are transported into the Yellow and the East/Japan Seas via the Tsushima Warm Current (TWC), which is a branch of the Kuroshio Current system (Umezawa et al. 2014). The massive nutrient load provided by the Changjiang River leads to high biological production in the central ECS ecosystem (Zhai and Dai 2009; Chou et al. 
2013). During the summer, southerly winds drive Changjiang Discharge Water (CDW) into the nECS. CDW then enters the East/Japan Sea through the Korea Strait along with the TWC (Cho et al. 1997). The Yellow Sea Bottom Cold Water (YSBCW), which forms through winter cooling in the Yellow Sea, extends a considerable distance into the nECS (Lie 1984; Gong et al. 1996). The atmospheric $\mathrm{CO}_{2}$ sink (air to sea) during the summer in the nECS is significant (Wang et al. 2000; Shim et al. 2007; Kim et al. 2013a). All of these processes suggest that the summer in this region is particularly dynamic due to both active physical mixing and biogeochemical processes.

In spite of what is known it has become apparent that our present knowledge of nECS water column biogeochemical processes is insufficient for understanding what is occurring in this changeable environment. The Three-Gorges Dam (TGD), which spans the Changjiang River, was recently completed (July 2012). One study reported that the TGD (before and after the first filling phase in June 2003) caused central ECS primary production to decrease by $86 \%$ between 1998 and 2003, illustrating the strong influence of the Changjiang River system (Gong et al. 2006). Hence, the TGD's effect on the nECS marine ecosystem is now an important issue to both Korean and Chinese marine science communities (Gong et al. 2006; Jiao et al. 2007; Kim et al. 2009). A detailed understanding of the physical and biogeochemical processes associated with CDW prior to TGD construction is necessary to evaluate the constructions anthropogenic effects. Observations from summer months are best suited to address this issue, as CDW is largely found in the nECS (Kim et al. 2005) during the summer. Dissolved inorganic phosphate (DIP) is an ideal variable for furthering our understanding of CDW cycles in the nECS.

Despite being a non-conservative parameter, DIP, the dominant phosphorus species in seawater, has relatively simple source (i.e., river input and remineralization) and sink (i.e., biological uptake and sediment burial) pathways in the marine environment (Tyrrell 1999). For this reason DIP has been widely used as a tracer to determine ocean circulation and biogeochemical processes (e.g., tracing ocean conveyor systems and estimating the remineralization rates) (Broecker and Peng 1982; Broecker 1991; Sarmiento and Gruber 2006). DIP is an essential ocean variable (http://iocgoos-oopc.org/obs/ecv.php) measured routinely on scientific research cruises.

The main goals of this research are to (1) estimate the quantities of remineralized phosphate using an historical summer hydrographic dataset of observations obtained before TGD construction and (2) infer the nECS summer remineralization rate.

\section{STUDY AREA AND DATA}

The study area from $30-34^{\circ} \mathrm{N}, 124-127^{\circ} \mathrm{E}$ in the nECS (Fig. 1) is described using a hydrographic cruise conducted from 25 August to 01 September 1997 on the $R / V$ Tam-Yang. Seawater temperature (T) and salinity (S) were measured at 39 stations using the SBE 911 plus CTD

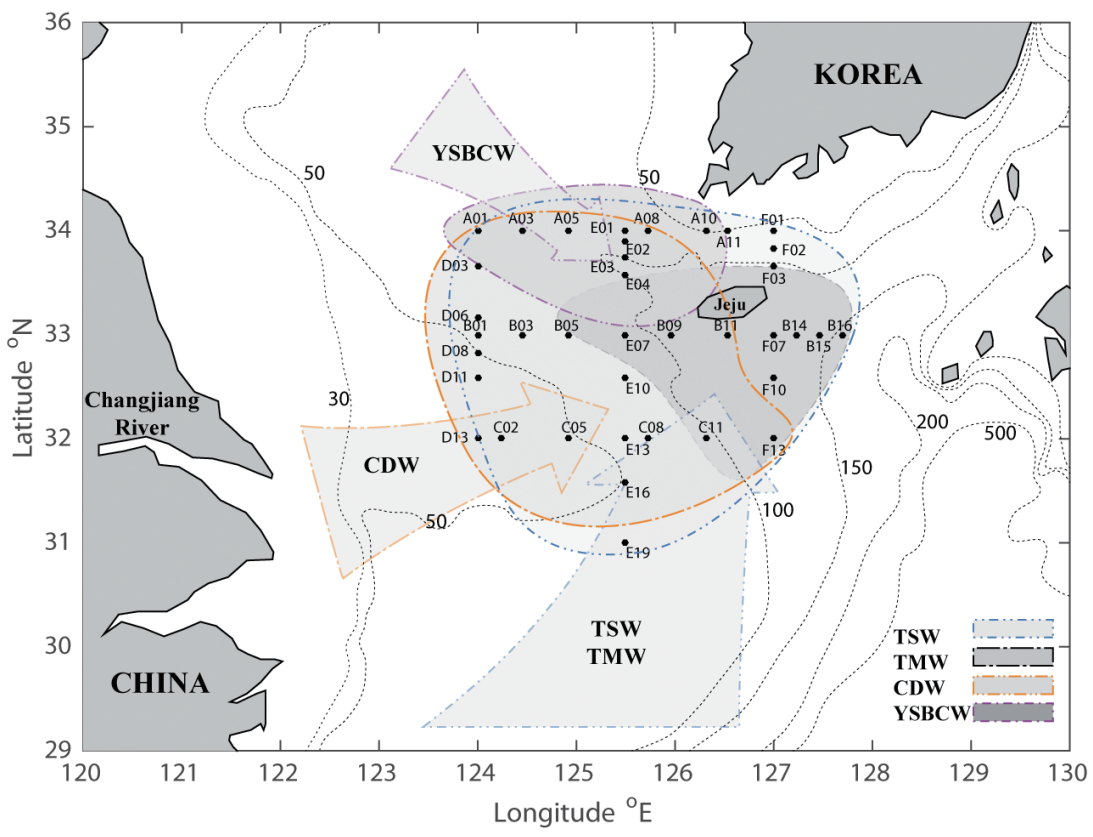

Fig. 1. Map illustrating the study area and locations observed in the August 1997 dataset. Black dots indicate hydrographic stations used in the analysis. Arrows indicate schematic flow of the end-members [CDW, TS(M)W, and YSBCW] used for the water mass analysis. The orientation of the arrows indicating water mass flows are based on the water mass mixing ratio distribution. CDW: Changjiang Discharge Water, TS(M)W: Tsushima Surface (Middle) Water, and YSBCW: Yellow Sea Bottom Cold Water. (Color online only) 
(conductivity-temperature-depth meter; Sea-Bird Electronics, Inc., Bellevue, WA, USA) outfitted with a rosette sampler. Seawater samples were collected in rinsed $125-\mathrm{mL}$ media bottles for nutrient analysis. Approximately $20-\mathrm{mL}$ aliquots were filtered through $0.2 \mu \mathrm{m}$ pore-size syringe filters for nutrient analysis after discarding the first $5 \mathrm{~mL}$ to rinse the filter. The remaining samples were frozen in $15-\mathrm{mL}$ plastic centrifuge tubes until analysis. Nutrient samples were analyzed within one week of the cruise. Nutrient concentrations were measured using an Alpkem continuous flow auto-analyzer (Kranj, Slovenia). We used T, S, and DIP data for our analysis.

\section{METHODS}

\subsection{Estimation of Remineralized Phosphate}

As physical mixing and biogeochemical processes determine the characteristics of oceanic parameters (Anderson and Sarmiento 1994; Kim et al. 2013b), measured DIP concentrations ([DIP $]_{\text {measured }}$ ) can be expressed as (Fig. 2):

$[\mathrm{DIP}]_{\text {measured }}=[\mathrm{DIP}]_{\text {mixing }}+[\mathrm{DIP}]_{\text {remineralized }}$

where $[\mathrm{DIP}]_{\text {mixing }}$ is the amount of DIP contributed by physical mixing, and [DIP] $]_{\text {remineralized }}$ is the amount of DIP regenerated by remineralization. Here, $[D I P]_{\text {mixing }}$ was estimated as follows:

$[\mathrm{DIP}]_{\text {mixing }}=\sum_{i=1}^{n} x_{i} \cdot\left[\mathrm{DIP} \mathrm{EM}_{i}\right.$

where $x_{i}$ represents the relative mixing ratio among $n$ different end-members that participate in the physical mixing process in the study area, and $\left[\mathrm{DIP}_{\mathrm{EM}}\right]_{i}$ is the defined DIP end-member characteristics. Physical mixing ratio estimation is explained in section 3.2. Combining Eq. (2) with Eq. (1), [DIP $]_{\text {remineralized }}$ is estimated as:

$[\mathrm{DIP}]_{\text {remineralized }}=[\mathrm{DIP}]_{\text {measured }}-\sum_{i=1}^{n} x_{i} \cdot\left[\mathrm{DIP} \mathrm{EM}_{i}\right.$

\subsection{Estimation of Physical Mixing Ratios}

\subsubsection{Physicochemical Characteristics of the End-Members}

As $\mathrm{T}$ and $\mathrm{S}$ are generally conservative parameters, not influenced by biological activity, a T-S diagram can be used for water mass analysis. Here, physical mixing in the study is described by the combination of four different endmembers (Fig. 3): high $\mathrm{T}$ and low $\mathrm{S}$ water (EM1), low $\mathrm{T}$ and low $\mathrm{S}$ water (EM2), low $\mathrm{T}$ and high $\mathrm{S}$ water (EM3), and high $\mathrm{T}$ and high $\mathrm{S}$ water (EM4). Due to its characteristic freshwater $(\mathrm{S} \approx 0)$, we defined EM1 as CDW (Gong et al. 1996). EM2 was defined as YSBCW because during the summer this water mass, which is typically characterized by $\mathrm{T}<10^{\circ} \mathrm{C}$ and $\mathrm{S}<33.7$, extends to near Jeju Island in the nECS (Zhang et al. 2008; Park et al. 2011). Tsushima Warm Water $(\mathrm{S}>34.5)$ is the dominant water mass occupying the surface and mid-depth levels in the study area, but its high vs. low $\mathrm{T}$ characteristics differs with depth (Chen et al. 1995; Chen 1996). EM3 and EM4 are therefore defined as Tsushima Middle Water (TMW) and Tsushima Surface Water (TSW), respectively.

DIP concentration in CDW was extrapolated from the relationship between DIP and S by Tian et al. (1993). Dilution of the CDW due to low nutrient ambient seawater mixing is fairly well described using a DIP linear regression as a function of salinity (i.e., DIP $\left[\mu \mathrm{mol} \mathrm{L}^{-1}\right]=0.019 \times \mathrm{S}+$ 0.799 , within salinity range of $0<\mathrm{S}<25$ ) (Tian et al. 1993). We assigned a DIP concentration of $0.02 \mu \mathrm{mol} \mathrm{L}^{-1}$ to TSW and TMS to reflect these Kuroshio waters with very low DIP concentration (Chen 1996). The DIP concentration in YSBCW was assigned a value of $0.4 \mu \mathrm{mol} \mathrm{L}^{-1}$, as adopted from Chen (1996). The physicochemical characteristics of each defined end-member are summarized in Table 1.

\subsubsection{The Four End-Member Mixing Model}

As described above four different end-members in the study area were distinguished through the definition of their physical characteristics (Fig. 3 and Table 1). The

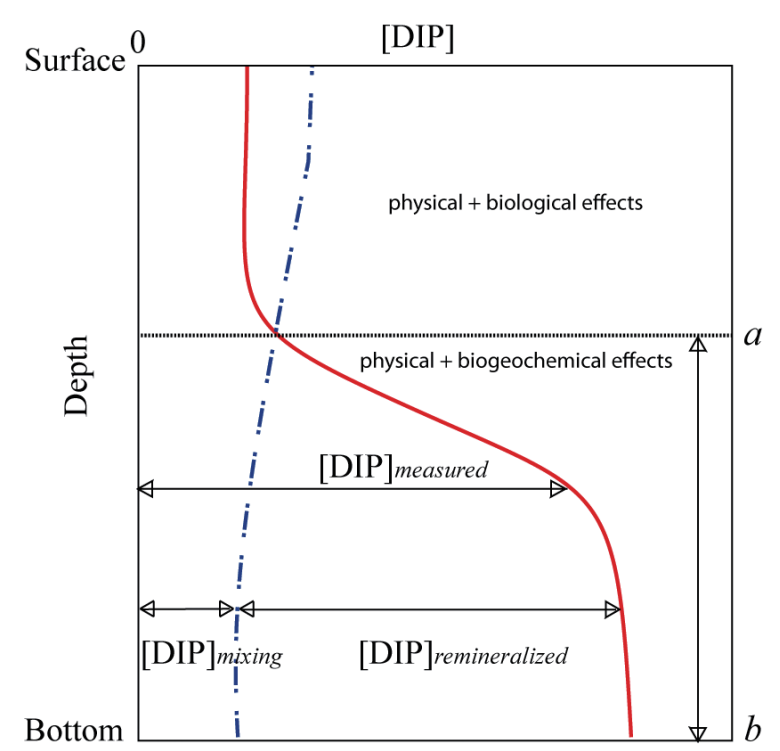

Fig. 2. Conceptual diagram used to estimate the quantity of remineralized phosphate $\left([\mathrm{DIP}]_{\text {remineralized }}\right)$. Red solid line indicates measured phosphate ([DIP $]_{\text {measured }}$ ). Black dash-dot line represents the phosphate concentration contributed by physical mixing among the different water masses $\left([\mathrm{DIP}]_{\text {mixing }}\right)$. The quantity of $[\mathrm{DIP}]_{\text {remineralized }}$ is computed as the difference between $[\mathrm{DIP}]_{\text {measured }}$ and $[\mathrm{DIP}]_{\text {mixing }}$ from the depth $(a)$ where $[\mathrm{DIP}]_{\text {measured }}$ is greater than $[\mathrm{DIP}]_{\text {mixing }}$ to the bottom $(b)$. (Color online only) 


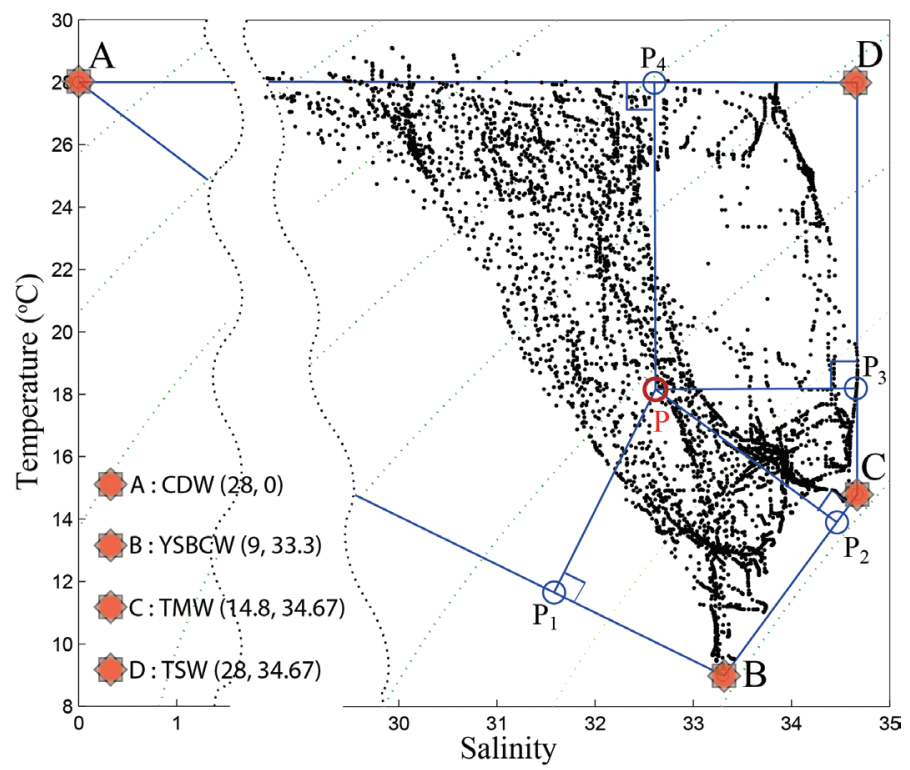

Fig. 3. Temperature-salinity diagram with associated sigma- $t$ (green contour lines) for the study area observed in August 1997 . Red stars represent the four end-members used for the water mass analysis ( $\mathrm{A}, \mathrm{B}, \mathrm{C}$, and $\mathrm{D})$ and describe the four corners of a tetragon. The positions $\mathrm{P}_{1}-\mathrm{P}_{4}$ lie along lines that are perpendicular to the sides of tetragon and pass through point $\mathrm{P}$. The distances $\mathrm{PP}_{1}-\mathrm{PP}_{4}$ discussed in the text (section 3.2.2) are the distances between $\mathrm{P}$ and $\mathrm{P}_{1}-\mathrm{P}_{4}$, while the distances $\mathrm{P}_{1} \mathrm{~A}-\mathrm{P}_{1} \mathrm{~B}, \mathrm{P}_{2} \mathrm{~B}-\mathrm{P}_{2} \mathrm{C}, \mathrm{P}_{3} \mathrm{C}-\mathrm{P}_{3} \mathrm{D}$, and $\mathrm{P}_{4} \mathrm{~A}-\mathrm{P}_{4} \mathrm{D}$ are the distances between the positions $\mathrm{P}_{1}-\mathrm{P}_{4}$ and each corner of the polygon. (Color online only)

Table 1. Physicochemical characteristics of the end-members (EM) used to calculate water mass mixing and to estimate remineralized phosphate in the northern East China Sea.

\begin{tabular}{cccc}
\hline EM & Temperature $\left({ }^{\circ} \mathbf{C}\right)$ & Salinity & Phosphate $\left(\boldsymbol{\mu m o l ~ \mathbf { L } ^ { - 1 } )}\right.$ \\
\hline CDW & $28.0 \pm 0.14$ & $0.00 \pm 0.00$ & $0.80 \pm 0.04$ \\
TSW & $28.0 \pm 0.13$ & $34.67 \pm 0.35$ & $0.02 \pm 0.01$ \\
TMW & $14.8 \pm 0.07$ & $34.67 \pm 0.35$ & $0.02 \pm 0.01$ \\
YSBCW & $9.0 \pm 0.04$ & $33.30 \pm 0.33$ & $0.40 \pm 0.01$ \\
\hline
\end{tabular}

Note: CDW: Changjiang Discharge Water, TS(M)W: Tsushima Surface (Middle) Water, YSBCW: Yellow Sea Bottom Cold Water.

four end-member mixing models developed by Chen et al. (1995) were used to estimate the mixing ratios of different end-members providing a physically sensible representation of the physical mixing processes in the shelf region. Here, we briefly describe the four end-member mixing models. The basic assumption is that the observed data are the result of mixing by the four different end-members constrained by mass conservation $\left(\sum_{i=1}^{4} x_{i}=1\right)$. The model calculates the fractions between the distances from the observed data $(\mathrm{P})$ on the T-S diagram to the projected positions $\left(\mathrm{P}_{1}-\mathrm{P}_{4}\right)$ perpendicular to each side of the tetragon and the distances from the projected positions $\left(\mathrm{P}_{1}-\mathrm{P}_{4}\right)$ to each end-member (A, B, C, and D) defined on the T-S diagram (Fig. 3). The fractions are presented as mixing ratios $\left(x_{i}\right)$. Based on Fig. 3 the mixing ratios of each end-member are expressed mathematically as:

$$
\begin{aligned}
& x_{\mathrm{EM} 1}=\left(\frac{\overline{\mathrm{P}_{1} \mathrm{~B}}}{\overline{\mathrm{AB} \cdot} \cdot \overline{\mathrm{PP}_{1}}}+\frac{\overline{\mathrm{P}_{4} \mathrm{D}}}{\overline{\mathrm{AD}} \cdot \overline{\mathrm{PP}_{4}}}\right) \times\left(\sum_{i=1}^{4} \frac{1}{\overline{\mathrm{PP}_{i}}}\right)^{-1} \\
& x_{\mathrm{EM} 2}=\left(\frac{\overline{\mathrm{P}_{1} \mathrm{~A}}}{\overline{\mathrm{AB}} \cdot \overline{\mathrm{PP}_{1}}}+\frac{\overline{\mathrm{P}_{2} \mathrm{C}}}{\overline{\mathrm{BC}} \cdot \overline{\mathrm{PP}_{2}}}\right) \times\left(\sum_{i=1}^{4} \frac{1}{\overline{\mathrm{PP}}_{i}}\right)^{-1} \\
& x_{\mathrm{EM} 3}=\left(\frac{\overline{\mathrm{P}_{2} \mathrm{~B}}}{\overline{\mathrm{BC}} \cdot \overline{\mathrm{PP}_{2}}}+\frac{\overline{\mathrm{P}_{3} \mathrm{D}}}{\overline{\mathrm{CD}} \cdot \overline{\mathrm{PP}_{3}}}\right) \times\left(\sum_{i=1}^{4} \frac{1}{\overline{\mathrm{PP}}_{i}}\right)^{-1}
\end{aligned}
$$

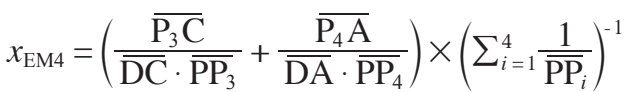

where the distances $\mathrm{PP}_{1}-\mathrm{PP}_{4}$ are the distances between $\mathrm{P}$ and $\mathrm{P}_{1}-\mathrm{P}_{4}$, and the distances $\mathrm{P}_{1} \mathrm{~A}-\mathrm{P}_{1} \mathrm{~B}, \mathrm{P}_{2} \mathrm{~B}-\mathrm{P}_{2} \mathrm{C}, \mathrm{P}_{3} \mathrm{C}-\mathrm{P}_{3} \mathrm{D}$, and $\mathrm{P}_{4} \mathrm{~A}-\mathrm{P}_{4} \mathrm{D}$ are the distances between the positions $\mathrm{P}_{1}-\mathrm{P}_{4}$ 
and each corner of the polygon. The details are described in Chen et al. (1995). A schematic representation of the flow of the end-members is included on the station map based on the distributions of the end-member mixing ratios (Fig. 1).

\subsubsection{Limitations on Physical Mixing Ratio Estimation}

We estimated the physical mixing ratios of the four different end-members (CDW, TSW, TMW, and YSBCW) using the physicochemical characteristics (Table 1) and the four end-member mixing models. The end-member definitions are critical to physical mixing ratio estimation because the ratios can be under- or overestimated if inappropriate information is used in the mixing model. To validate the estimated mixing ratios a correlation analysis was performed comparing observed $\mathrm{T}(\mathrm{S})$ to estimated $\mathrm{T}(\mathrm{S})\left[=\sum_{i=1}^{4} x_{i} \cdot \mathrm{T}(\mathrm{S})_{\mathrm{EM} i}\right.$, where $\mathrm{T}(\mathrm{S})_{\mathrm{EM} i}$ are $\mathrm{T}(\mathrm{S})$ characteristics of the end-members]. The correlation coefficients were $>0.9$ throughout the water column. In addition, the influence of variation in the endmember characteristics within the standard deviations on the mixing ratio results was $<5 \%$. However, potential error could occur in terms of the defined end-member characteristics, so we emphasize that the end-member characteristics defined for our analysis are only valid in the study area for the summer of 1997.

\section{RESULTS AND DISCUSSION}

\subsection{Magnitude of Remineralized Phosphate}

The discrete [DIP] $]_{\text {measured }}$ concentrations from the 1997 summer cruise in the nECS were vertically interpolated in depth space using a second order polynomial curve fitting function. The observations were extrapolated on average to within $2 \mathrm{~m}$ of the bottom (Fig. 2). Equation (3) was used to decompose the vertical profile of $[\mathrm{DIP}]_{\text {measured }}$ into $[\mathrm{DIP}]_{\text {mixing }}$ and $[\mathrm{DIP}]_{\text {remineralized }}$ for each hydrographic station (Fig. 4). The concentration of [DIP] $]_{\text {measured }}$ was depleted (i.e., [DIP] mixing $>[\mathrm{DIP}]_{\text {measured }}$ in the mixed layer due to high biological activity at the surface. Below the mixed layer, $[\mathrm{DIP}]_{\text {remineral }}$ ized increased with depth, indicating that organic matter decomposition was active in the water column (i.e., downward flux) and at the sediment surface (i.e., upward flux) (Krom and Berner 1981). Assuming that DIP is regenerated from the water column and surface sediments, the column inventory of $[D I P]_{\text {remineralized }}$ can be estimated as:

$[\mathrm{DIP}]_{\text {remineralized }}^{\text {invery }}\left(\mathrm{mmol} \mathrm{m}^{-2}\right)=\int_{a}^{b}[\mathrm{DIP}]_{\text {remineralized }} d z$

where $a$ is the depth where $[\mathrm{DIP}]_{\text {measured }}>[\mathrm{DIP}]_{\text {mixing }}$, and $b$ is the bottom depth. We mapped the spatial distribution of $[D I P]_{\text {reminerralized }}^{\text {invertig. 5). }}$ (F)

During the summer of 1997 in the nECS, the $[D I P]_{\text {remineralized }}^{\text {invertion }}$ magnitude ranged from 0.8 (Sta. C05 lying in the path of CDW) to 42.4 (Sta. B14 southeast of Jeju Island) mmol $\mathrm{P} \mathrm{m}^{-2}$ (mean: $15.2 \pm 12.0 \mathrm{mmol} \mathrm{P} \mathrm{m}^{-2}$ ). The largest [DIP] $]_{\text {remineralized }}^{\text {inventy }}$ values (i.e., greater than the mean) were mainly distributed around Jeju Island, corresponding to the TWC (TSW + TMW) distribution (Fig. 1), whereas low magnitude [DIP] $]_{\text {remineralized }}^{\text {inverti.e., less than the mean) }}$

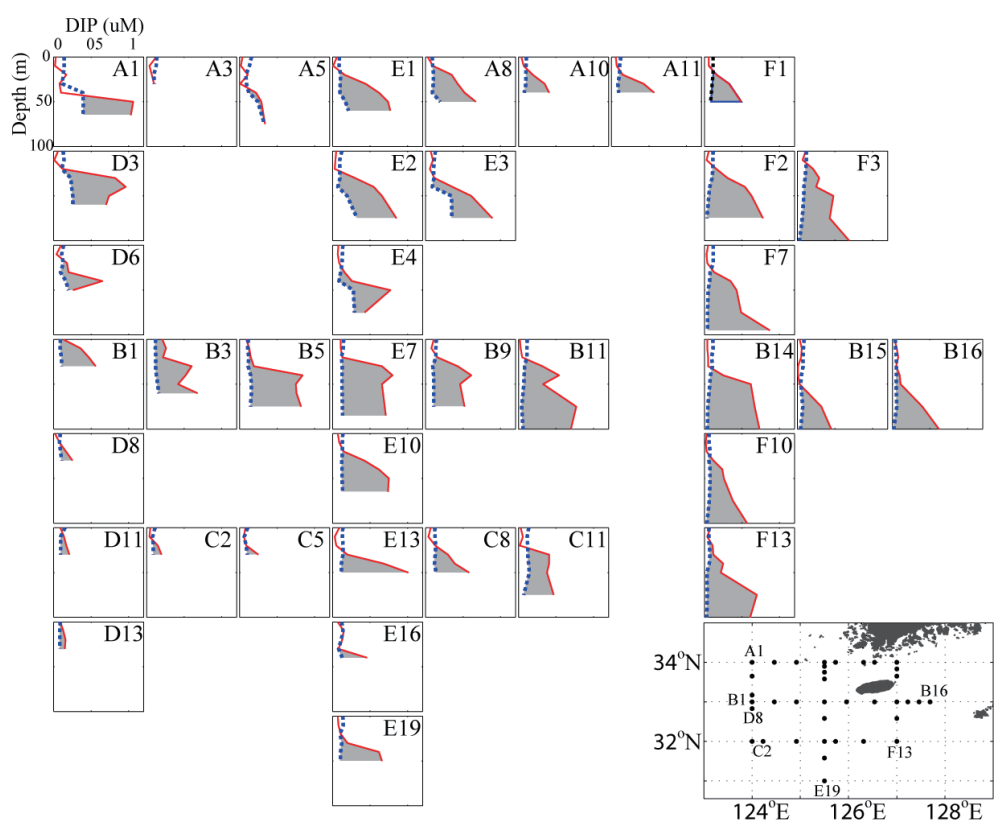

Fig. 4. Vertical profiles of $[\mathrm{DIP}]_{\text {measured }}$ (black solid lines) with $[\mathrm{DIP}]_{\text {mixing }}$ (black dotted lines) and $[\mathrm{DIP}]_{\text {remineralized }}$ (gray areas) for each hydrographic station in the study area. The discrete $[\mathrm{DIP}]_{\text {measured }}$ concentrations were vertically interpolated in depth space using a second order polynomial curve fitting function and were then extrapolated to the bottom depth. (Color online only) 


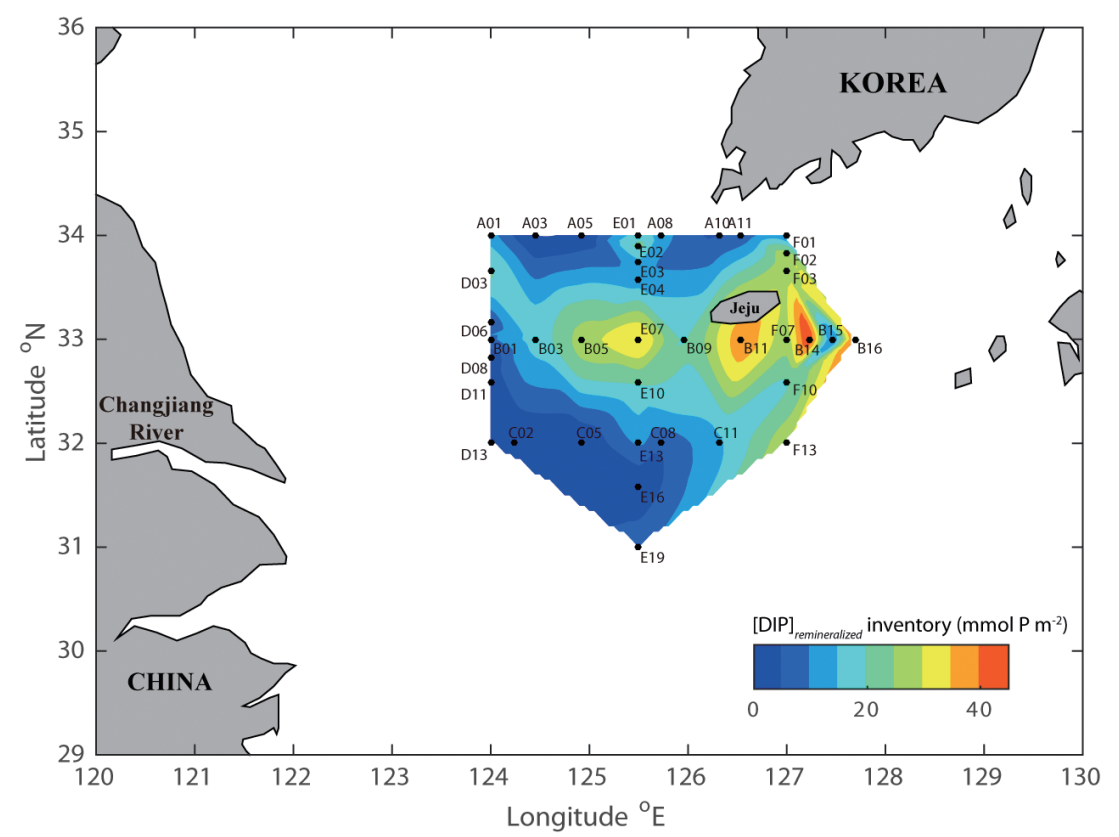

Fig. 5. Spatial distribution of estimated column inventory $\left(\mathrm{mmol} \mathrm{P}^{-2}\right)$ of $[\mathrm{DIP}]_{\text {remineralized }}$ in the study area. (Color online only)

was predominantly distributed in the region influenced by CDW (Fig. 5). This result would seem to oppose the idea that $\mathrm{CDW}$ is the main driver stimulating primary production in the nECS as has been previously suggested (Chou et al. 2013; Tseng et al. 2014).

To better understand the juxtaposition of our results with earlier findings, other datasets were sought. One advantage of satellite-based chlorophyll- $a$ information is that it can be used to infer primary production over a large area at a particular time (Falkowski et al. 1998). Here, the satellite-based summer chlorophyll- $a$ concentrations provided by SeaWiFs (Sea-viewing Wide Field-of-view Sensor) in the nECS were used to estimate primary production in the region. As SeaWiFs was launched in August of 1997, just missing our observation window, the mean August chlorophyll- $a$ distribution during the 1998 - 2002 period (before the first filling phase of TGD in Jun 2003) was used for comparison (Fig. 6). The distribution shows that chlorophyll- $a$ concentrations were high near the CDW source region. High primary production was driven by a massive nutrient load through the Changjiang River system. However, its influence was generally confined within the coastal region near the mouth of the Changjiang River (Chen et al. 1995), where most of the DIP was consumed by phytoplankton growth. In addition, particulate organic phosphorus (POP) may have been substantially removed by adsorption to suspended sediments as they sank to the bottom (Milliman et al. 1985). Shown here as an example, the brown color reproduced from a pseudo-color image from August 1999 suggests that suspended sediments were abundant and that this suspension is confined to the region near the mouth of the Changjiang River (see Fig. 7).
Meng et al. (2015) recently showed that DIP concentrations dramatically decrease $\left(\sim 3.0 \rightarrow 1.0 \rightarrow 0.5 \mu \mathrm{mol} \mathrm{L}^{-1}\right)$ as salinity increases (upstream to the mouth of the River and beyond, seaward: $\sim 0 \rightarrow 10 \rightarrow 25$ ), indicating strong DIP removal associated with the decreasing supply of POP (see their Fig. 3). All of these results support the hypothesis that rapid removal of organic phosphorus occurs near the Changjiang River mouth and the distance of our study area from the CDW source region ( $\sim 300 \mathrm{~km}$, Fig. 1) may bias our conclusion that the CDW influence on [DIP] $]_{\text {remineralized }}^{\text {invents }}$ is small. In summary, the summertime physical properties of CDW were traced within the study area. The biogeochemical influence of CDW was not especially large, most likely due to rapid biological uptake in the source region. Thus, based on the distribution of [DIP] $]_{\text {remineralized }}^{\text {invertory }}$ magnitude, it is likely that the TWC maintained primary production during the summer of 1997 in the study area. An interesting extension would be to investigate whether this balance in controls varies according to spatiotemporal variability in CDW influence.

\subsection{Inferred Remineralization Rate}

In the previous section, we estimated $[\mathrm{DIP}]_{\text {remineralized }}^{\text {invert }}$ $\left(\mathrm{mmol} \mathrm{P} \mathrm{m}{ }^{-2}\right)$ and discussed its spatial distribution. Here, $[D I P]_{\text {remineralized }}^{\text {invertor }}$ provides an opportunity to estimate the remineralization rate (RR) in terms of carbon $(C)$ by multiplying it by the $C / P\left(R_{C / P=106}\right)$ Redfield ratio. This calculation assumes that $[\mathrm{DIP}]_{\text {remineryalized }}^{\text {invert }}$ resulted from the downward flux in primary production from the depth where $[\mathrm{DIP}]_{\text {measured }}$ $>[D I P]_{\text {mixing }}$ during summer (June - August) in the study area. This assumption is based on summer water mass composition 


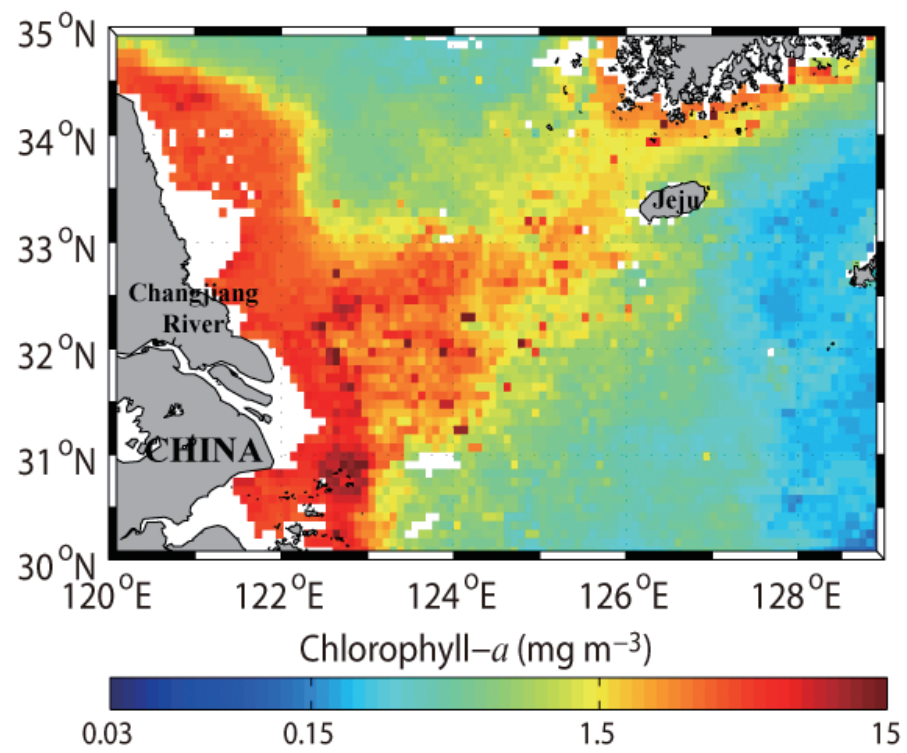

Fig. 6. Distribution of mean SeaWiFS August chlorophyll- $a$ concentrations during 1998 - 2002 in the northern East China Sea. (Color online only)

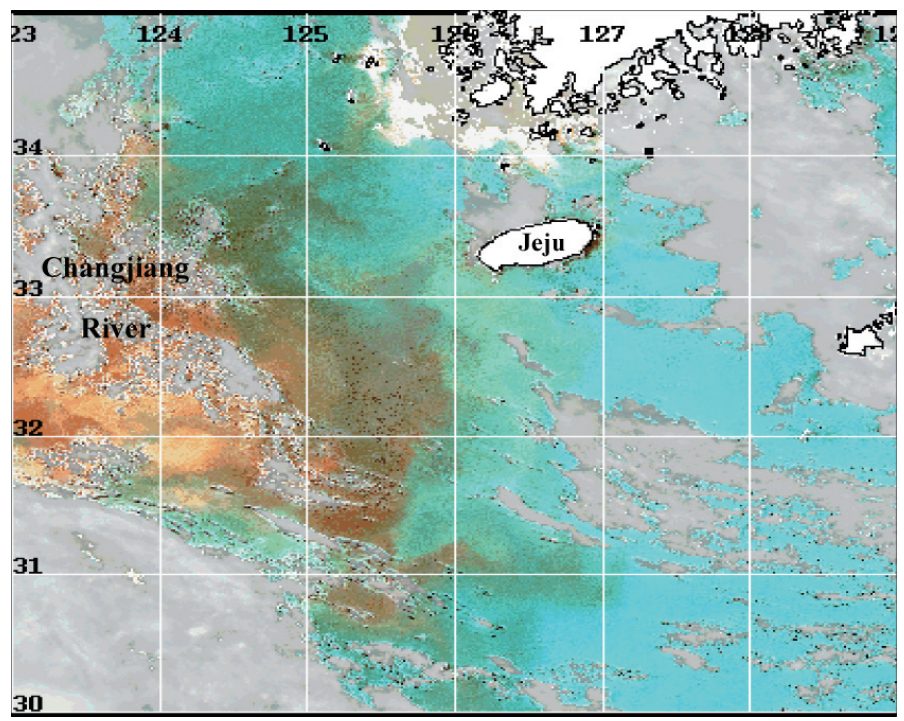

Fig. 7. A pseudo-colored image to estimate spatial distribution of suspended sediments in August 1999. The brown color suggests abundant suspended sediments. (Color online only)

maintenance in the region (Chen et al. 1995; Chen 1996; Kim et al. 2005) as well as the small differences in satellite-based primary production estimates during the summer season (June - August). Thus, summer RR is estimated as:

$$
\begin{aligned}
\mathrm{RR}\left(\mathrm{mmol} \mathrm{C} \mathrm{m}^{-2} \mathrm{~d}^{-1}\right)= & \left([\mathrm{DIP}]_{\text {remineralized }}^{\text {inventy }}\right) \times\left(\mathrm{R}_{\mathrm{C} / \mathrm{P}=106}\right) \\
& \times\left(\frac{1}{\text { summer period }_{=90 \text { days }}}\right)
\end{aligned}
$$

RR magnitude ranged from $\sim 1$ (Sta. C05) to 50 (Sta. B14) mmol C m $\mathrm{d}^{-1}$ (mean: $18 \pm 14 \mathrm{mmol} \mathrm{C} \mathrm{m} \mathrm{d}^{-2}$ in the study area).
Primary production was not measured in the study area before TGD construction, but a summertime estimate observed in June - July 1998 is available for the entire ECS (mean: $\sim 80 \mathrm{mmol} \mathrm{C} \mathrm{m}^{-2} \mathrm{~d}^{-1}$ ) (Gong et al. 2003). In addition, we have the SeaWiFs satellite-based mean summer (June - August) primary production estimate for the period of 1998 - 2002: $\sim 120 \mathrm{mmol} \mathrm{C} \mathrm{m}^{-2} \mathrm{~d}^{-1}$. Assuming that the estimated RR is derived mainly from the downward flux of primary production (i.e., remineralization rate $\approx$ export production), these two estimates can be used to obtain an estimated range for the $e$-ratio (export production/primary production; Sarmiento and Gruber 2006) in the nECS, 
$0.15 \pm 0.12-0.23 \pm 0.18$. Note that the estimated $e$-ratio could be considered an upper $e$-ratio limit in the study area. The $e$-ratio is approximately equal to the $f$-ratio (Dugdale and Goering 1967). The $f$-ratio is defined as the ratio of new production divided by primary production, so often this relationship is called the ef-ratio (Laws et al. 2000; Sarmiento and Gruber 2006). Our estimated summer ef-ratio in the $\mathrm{nECS}$ before TGD construction is comparable to the global mean of 0.21 , which is characterized as a mesotrophic-eutrophic condition $(e f$-ratio $=0.18-0.36)$ [see Table 4.4.2 in Sarmiento and Gruber (2006)].

\section{CONCLUSIONS}

We estimated the quantities of remineralized phosphate in the water column during the summer in the nECS in a snapshot study using hydrographic observations from August 1997. The remineralized phosphate column inventory was estimated to range from 0.8 to $42.4 \mathrm{mmol} \mathrm{P} \mathrm{m}^{-2}$ (mean: $15.2 \pm 12.0 \mathrm{mmol} \mathrm{P} \mathrm{m}^{-2}$ ). The highest values were distributed in the regions strongly influenced by the TWC, indicating that the TWC contributed to primary production in the study area, at least during the summer of 1997. The summertime remineralization rate estimated in terms of $\mathrm{C}$ was $18 \pm 14 \mathrm{mmol} \mathrm{C} \mathrm{m} \mathrm{d}^{-1}$. The estimated $e f$-ratio was $0.15-0.23$, suggesting that the summertime nECS was characterized as being under mesotrophic-eutrophic conditions (ef-ratio $=0.18-0.36$ ) before TGD construction. As the nECS shows substantial vulnerability to external forcing, further studies should investigate how the ef-ratio has changed since our study after TGD construction.

Acknowledgements We thank all of those who contributed to the summer South Sea hydrographic cruise conducted in August 1997. We thank the anonymous reviewers for their valuable comments, which improved our manuscript considerably. T. Lee was supported by 2-Year Research Grant of Pusan National University. H.-C. Kim was partly supported by KOPRI project (PG15010). I.-N. Kim was partly supported by the National Research Foundation of Korea (NRF) grant funded by the Korea government (MSIP) (No. 2015R1C1A1A01052051). K.-T. Park was partly supported by KOPRI project (PE17010). J.-H. Kim was partly supported by the program of "Management of Marine Organisms Causing Ecological Disturbance and Harmful Effects" funded by KIMST/MOF. A.M. Macdonald's contribution was supported by NOAA grant: \#NA110AR4310063 and NSF grant: \#OCE-1059881. The first two authors (Hyun-Cheol Kim and Il-Nam Kim) contributed equally to this work.

\section{REFERENCES}

Anderson, L. A. and J. L. Sarmiento, 1994: Redfield ratios of remineralization determined by nutrient data analysis. Global Biogeochem. Cycles, 8, 65-80, doi: 10.1029/93GB03318. [Link]

Broecker, W. S., 1991: The great ocean conveyor. Oceanography, 4, 79-89, doi: 10.5670/oceanog.1991.07. [Link]

Broecker, W. S. and T. H. Peng, 1982: Tracers in the Sea, Lamont-Doherty Geological Observatory, Columbia University, Palisades, New York, 702 pp.

Chen, C. T. A., 1996: The Kuroshio intermediate water is the major source of nutrients on the East China Sea continental shelf. Oceanol. Acta, 19, 523-527.

Chen, C. T. A., R. Ruo, S. C. Pai, C. T. Liu, and G. T. F. Wong, 1995: Exchange of water masses between the East China Sea and the Kuroshio off northeastern Taiwan. Cont. Shelf Res., 15, 19-39, doi: 10.1016/02784343(93)E0001-O. [Link]

Cho, H. J., C. H. Moon, H. S. Yang, W. B. Kang, and K. W. Lee, 1997: Regeneration processes of nutrients in the polar front area of the East Sea. III. Distribution patterns of water masses and nutrients in the middlenorthern East Sea of Korea in October, 1995. J. Korean Fish. Soc., 30, 393-407. (in Korean)

Chou, W. C., G. C. Gong, W. J. Cai, and C. M. Tseng, 2013: Seasonality of $\mathrm{CO}_{2}$ in coastal oceans altered by increasing anthropogenic nutrient delivery from large rivers: Evidence from the Changjiang-East China Sea system. Biogeosciences, 10, 3889-3899, doi: 10.5194/ bg-10-3889-2013. [Link]

Dugdale, R. C. and J. J. Goering, 1967: Uptake of new and regenerated forms of nitrogen in primary productivity. Limnol. Oceanogr., 12, 196-206, doi: 10.4319/ lo.1967.12.2.0196. [Link]

Falkowski, P. G., R. T. Barber, and V. Smetacek, 1998: Biogeochemical controls and feedbacks on ocean primary production. Science, 281, 200-206, doi: 10.1126/ science.281.5374.200. [Link]

Gong, G. C., Y. L. L. Chen, and K. K. Liu, 1996: Chemical hydrography and chlorophyll $a$ distribution in the East China Sea in summer: Implications in nutrient dynamics. Cont. Shelf Res., 16, 1561-1590, doi: 10.1016/0278-4343(96)00005-2. [Link]

Gong, G. C., Y. H. Wen, B. W. Wang, and G. J. Liu, 2003: Seasonal variation of chlorophyll $a$ concentration, primary production and environmental conditions in the subtropical East China Sea. Deep-Sea Res. Part II-Top. Stud. Oceanogr., 50, 1219-1236, doi: 10.1016/S09670645(03)00019-5. [Link]

Gong, G. C., J. Chang, K. P. Chiang, T. M. Hsiung, C. C. Hung, S. W. Duan, and L. A. Codispoti, 2006: Reduction of primary production and changing of nutrient ratio in the East China Sea: Effect of the Three Gorges Dam? Geophys. Res. Lett., 33, L07610, doi: 10.1029/2006GL025800. [Link]

Gruber, N., 2015: Ocean biogeochemistry: Carbon at the 
coastal interface. Nature, 517, 148-149, doi: 10.1038/ nature 14082. [Link]

Jiao, N., Y. Zhang, Y. Zeng, W. D. Gardner, A. V. Mishonov, M. J. Richardson, N. Hong, D. Pan, X. H. Yan, Y. H. Jo, C. T. A. Chen, P. Wang, Y. Chen, H. Hong, Y. Bai, X. Chen, B. Huang, H. Deng, Y. Shi, and D. Yang, 2007: Ecological anomalies in the East China Sea: Impacts of the Three Gorges Dam? Water Res., 41, 12871293, doi: 10.1016/j.watres.2006.11.053. [Link]

Kim, D., J. H. Shim, J. A. Lee, and Y. C. Kang, 2005: The distribution of nutrients and chlorophyll in the northern East China Sea during the spring and summer. Ocean Polar Res., 27, 251-263, doi: 10.4217/ OPR.2005.27.3.251. (in Korean with English abstract) [Link]

Kim, D., S. H. Choi, K. H. Kim, J. Shim, S. Yoo, and C. H. Kim, 2009: Spatial and temporal variations in nutrient and chlorophyll- $a$ concentrations in the northern East China Sea surrounding Cheju Island. Cont. Shelf Res., 29, 1426-1436, doi: 10.1016/j.csr.2009.03.012. [Link]

Kim, D., S. H. Choi, J. Shim, K. H. Kim, and C. H. Kim, 2013a: Revisiting the seasonal variations of seaair $\mathrm{CO}_{2}$ fluxes in the northern East China Sea. Terr. Atmos. Ocean. Sci., 24, 409-419, doi: 10.3319/ TAO.2012.12.06.01(Oc). [Link]

Kim, I. N., D. H. Min, and A. M. Macdonald, 2013b: Water column denitrification rates in the oxygen minimum layer of the Pacific Ocean along $32^{\circ} \mathrm{S}$. Global Biogeochem. Cycles, 27, 816-827, doi: 10.1002/gbc.20070. [Link]

Krom, M. D. and R. A. Berner, 1981: The diagenesis of phosphorus in a nearshore marine sediment. Geochim. Cosmochim. Acta, 45, 207-216, doi: 10.1016/00167037(81)90164-2. [Link]

Laws, E. A., P. G. Falkowski, W. O. Smith, H. Ducklow, and J. J. McCarthy, 2000: Temperature effects on export production in the open ocean. Global Biogeochem. Cycles, 14, 1231-1246, doi: 10.1029/1999GB001229. [Link]

Lie, H. J., 1984: A note on water masses and general circulation in the Yellow Sea (Hwanghae). J. Oceanological Soc. Kor., 19, 187-194.

Liu, K. K., L. Atkinson, R. A. Quiñones, and L. TalaueMcManus, 2010: Biogeochemistry of continental margins in a global context. In: Liu, K. K., L. Atkinson, R. A. Quiñones, L. Talaue-McManus (Eds.), Carbon and Nutrient Fluxes in Continental Margins: A Global Synthesis, Springer Berlin Heidelberg, 3-24, doi: 10.1007/978-3-540-92735-8_1. [Link]

Meng, J.,Z. Yu, Q. Yao, T. S. Bianchi, A.Paytan, B.Zhao, H. Pan, and P. Yao, 2015: Distribution, mixing behavior, and transformation of dissolved inorganic phosphorus and suspended particulate phosphorus along a salinity gradient in the Changjiang Estuary. Mar. Chem., 168, 124-134, doi: 10.1016/j.marchem.2014.09.016. [Link]
Milliman, J. D., H. Shen, Z. Yang, and R. H. Meade, 1985: Transport and deposition of river sediment in the Changjiang estuary and adjacent continental shelf. Cont. Shelf Res., 4, 37-45, doi: 10.1016/02784343(85)90020-2. [Link]

Park, S., P. C. Chu, and J. H. Lee, 2011: Interannual-tointerdecadal variability of the Yellow Sea Cold Water Mass in 1967-2008: Characteristics and seasonal forcings. J. Mar. Syst., 87, 177-193, doi: 10.1016/j. jmarsys.2011.03.012. [Link]

Sarmiento, J. L. and N. Gruber, 2006: Ocean Biogeochemical Dynamics, Princeton University Press, Princeton, New Jersey, 528 pp.

Shim, J., D. Kim, Y. C. Kang, J. H. Lee, S. T. Jang, and C. H. Kim, 2007: Seasonal variations in $p \mathrm{CO}_{2}$ and its controlling factors in surface seawater of the northern East China Sea. Cont. Shelf Res., 27, 2623-2636, doi: 10.1016/j.csr.2007.07.005. [Link]

Tian, R. C., F. X. Hu, and J. M. Martin, 1993: Summer nutrient fronts in the Changjiang (Yantze River) Estuary. Estuar. Coast. Shelf Sci., 37, 27-41, doi: 10.1006/ ecss.1993.1039. [Link]

Tseng, Y. F., J. Lin, M. Dai, and S. J. Kao, 2014: Joint effect of freshwater plume and coastal upwelling on phytoplankton growth off the Changjiang River. Biogeosciences, 11, 409-423, doi: 10.5194/bg-11-409-2014. [Link]

Tsunogai, S., S. Watanabe, and T. Sato, 1999: Is there a "continental shelf pump" for the absorption of atmospheric $\mathrm{CO}_{2}$ ? Tellus, 51B, 701-712, doi: 10.1034/ j.1600-0889.1999.t01-2-00010.x. [Link]

Tyrrell, T., 1999: The relative influences of nitrogen and phosphorus on oceanic primary production. Nature, 400, 525-531, doi: 10.1038/22941. [Link]

Umezawa, Y., A. Yamaguchi, J. Ishizaka, T. Hasegawa, C. Yoshimizu, I. Tayasu, H. Yoshimura, Y. Morii, T. Aoshima, and N. Yamawaki, 2014: Seasonal shifts in the contributions of the Changjiang River and the Kuroshio Current to nitrate dynamics in the continental shelf of the northern East China Sea based on a nitrate dual isotopic composition approach. Biogeosciences, 11, 1297-1317, doi: 10.5194/bg-11-1297-2014. [Link]

Wang, S. L., C. T. A. Chen, G. H. Hong, and C. S. Chung, 2000: Carbon dioxide and related parameters in the East China Sea. Cont. Shelf Res., 20, 525-544, doi: 10.1016/S0278-4343(99)00084-9. [Link]

Zhai, W. and M. Dai, 2009: On the seasonal variation of air - sea $\mathrm{CO}_{2}$ fluxes in the outer Changjiang (Yangtze River) Estuary, East China Sea. Mar. Chem., 117, 2-10, doi: 10.1016/j.marchem.2009.02.008. [Link]

Zhang, S. W., Q. Y. Wang, Y. Lü, H. Cui, and Y. L. Yuan, 2008: Observation of the seasonal evolution of the Yellow Sea Cold Water Mass in 1996-1998. Cont. ShelfRes., 28, 442-457, doi: 10.1016/j.csr.2007.10.002. [Link] 